\title{
Despite higher revision rate, MoM large- head THA offers better clinical scores than HR: 14-year results from a randomized controlled trial involving 48 patients
}

Lazaros Kostretzis, Martin Lavigne, Marc-Olivier Kiss, Maged Shahin, Janie Barry and Pascal-André Vendittoli (D)

\begin{abstract}
Background: The high failure rates of metal on metal (MoM) large diameter head total hip arthroplasty (LDH THA) and hip resurfacing (HR) prevented their long-term comparisons with regards to clinical outcome. Such knowledge would be important as ceramic LDH bearing is now available. With long-term follow-up, we investigated the difference in 1) patient-reported outcome measures (PROMs); 2) revision and adverse events rates, and 3) metal ion levels between MoM LDH THA and HR.
\end{abstract}

Methods: Forty-eight patients were randomized for LDH THA (24) or HR (24) with the same MoM articulation. At a mean follow-up of 14 years, we compared between groups different PROMs, the number of revisions and adverse events, whole blood Cobalt (Co) and Chromium ( $\mathrm{Cr}$ ) ion levels, and radiographic signs of implant dysfunction.

Results: LDH THA (all cases: revised and well-functioning) had significantly better WOMAC (94 versus $85, p=0.04$ ), and more frequently reported having no limitation $(p=0.04)$. LDH THA revision rate was $20.8 \%(5 / 24)$ versus $8.3 \%$ (2/24) for HR ( $p=0.4)$. Mean Co and $\mathrm{Cr}$ ion levels were higher in LDH THA compared to the HR (Co: $3.8 \mu \mathrm{g} / \mathrm{L}$ vs $1.7 \mu \mathrm{g} / \mathrm{L} ; \mathrm{P}=0.04$ and $\mathrm{Cr}: 1.9 \mu \mathrm{g} / \mathrm{L}$ vs $1.4 \mu \mathrm{g} / \mathrm{L}, p=0.1)$. On radiographic analyses, $2 \mathrm{LDH}$ THAs showed signs of adverse reaction to metal debris, whereas 1 loose femoral HR component was documented.

Conclusion: In the long-term, MoM LDH THA had a high trunnion related revision rate but nonetheless showed better PROMs compared to HR. Provided with a well-functioning modular junction, non-MoM LDH THA would offer an appealing option.

Trial registration: ClinicalTrials.gov (NCT04516239), August 18, 2020. Retrospectively registered.

Keywords: Hip resurfacing, Large diameter, Metal ions, Metal on metal, Patient reported outcome measures, Radiographic, Revision rate, Total hip arthroplasty

\footnotetext{
* Correspondence: pa.vendittoli@me.com

Surgery Department, Hôpital Maisonneuve-Rosemont, Montreal University,

5415 Boulevard de l'Assomption, Montréal, Québec H1T 2M4, Canada
}

C C The Author(s). 2021 Open Access This article is licensed under a Creative Commons Attribution 4.0 International License, which permits use, sharing, adaptation, distribution and reproduction in any medium or format, as long as you give appropriate credit to the original author(s) and the source, provide a link to the Creative Commons licence, and indicate if changes were made. The images or other third party material in this article are included in the article's Creative Commons licence, unless indicated otherwise in a credit line to the material. If material is not included in the article's Creative Commons licence and your intended use is not permitted by statutory regulation or exceeds the permitted use, you will need to obtain permission directly from the copyright holder. To view a copy of this licence, visit http://creativecommons.org/licenses/by/4.0/. The Creative Commons Public Domain Dedication waiver (http://creativecommons.org/publicdomain/zero/1.0/) applies to the data made available in this article, unless otherwise stated in a credit line to the data. 


\section{Background}

The favorable tribological properties of metal on metal (MoM) bearings promised, in the early 2000s, to reduce polyethylene wear-related osteolysis and improve joint stability [1]. This led to the reintroduction of hip resurfacing (HR) and the development of large diameter head total hip arthroplasty (LDH THA). In 2010, our institution was awarded the John Charnley award for our randomized controlled trial (RCT) comparing MoM HR with MoM LDH THA. In that study, we found similar performance on most functional tests (including formal gait analysis), and similar patient reported outcome measures (PROMs) between groups [2]. Moreover, no significant difference was observed between both groups and a control group without hip replacement. However, the mean follow-up of 14 months was short, and long term follow up may reveal different findings.

Unfortunately, clinical studies and national registries [3, 4] reported unacceptable rates of failure in the mid-term for most MoM HR and LDH THA. leading to recall and voluntary removal of these implants from the market [57]. However, design and technological improvements using other materials, like ceramic $[8,9]$ may have the potential to mitigate the limitations associated with $\mathrm{MoM}$ and may lead to resurgence of LDH THA and HR.

The purpose of this study was to compare HR and LDH THA randomized in our study after a mean follow-up of 14 years (12-15) regarding 1) PROMs, 2) revision and adverse events rates, and (3) systemic metal ion levels.

\section{Materials and methods Study design}

Between February 2006 and April 2007, 48 patients aged less than 70 years with degenerative hip joint disease were randomized for MoM HR (24) or LDH THA (24, Fig. 1). Patient demographics are presented in Table 1. The same original Durom acetabular cup (not the USA version) was implanted in all patients. A posterior approach was used for both interventions, with the short external rotators released from the greater trochanter and a posterior capsulotomy performed. In the HR group, the capsulotomy was completed circumferentially, the gluteus minimus was elevated from the ilium, and the gluteus maximus tendinous insertion on the femur was released in all men, but only when needed in women. For more details on the implants and surgical technique, a detailed protocol of the this RCT has been published previously [2]. The present study adhered to CONSORT guidelines.

\section{Assessment of outcomes}

At last follow-up, different PROMs were collected for patients enrolled in the study (including revised cases): WOMAC [10], UCLA activity score [11], Forgotten Joint
Score (FJS-12) [12], and Patient's Joint Perception (PJP) [13]. All implant revisions and adverse events during the follow-up period were recorded. Whole blood Cobalt (Co) and Chromium ( $\mathrm{Cr}$ ) ion measurements were performed in patients with original hip implants (not revised) and without other bodily metallic implants at the 1 year and last follow-up time frame. All samples were submitted for blinded analysis by an independent laboratory using a Finnigan MAT Element 2 high-resolution sector-field inductively coupled plasma mass spectrophotometer (Thermo Fisher Scientific GmbH, Bremen, Germany). The detection limits were $0.1 \mu \mathrm{g} / \mathrm{L}$ for $\mathrm{Cr}$ and $0.01 \mu \mathrm{g} / \mathrm{L}$ for Co. An anteroposterior (AP) radiograph of the pelvis with the legs positioned in $15^{\circ}$ of internal rotation and a cross-table lateral radiograph of the operated hip were taken at each follow-up visit and compared with immediate post-operative films by one author (LK) seeking for signs of implant dysfunction. Definite femoral stem loosening was defined by continuous lucent lines $>2 \mathrm{~mm}$, stem fracture, subsidence $>5 \mathrm{~mm}$, or a change in component angulation $>5^{\circ}$ [14-16]. Definite acetabular loosening was considered with continuous radiolucency $>2 \mathrm{~mm}$, component migration $>3 \mathrm{~mm}$ or angulation change $>5^{\circ}$ [17]. Heterotopic ossification grade was estimated according to the Brooker classification [18]. Description of radiolucent lines were done according to Amstutz zones [19] (HR) and Gruen zones [20] (LDH THA) for the femur, and Charnley-De Lee zones [21] for the acetabulum.

\section{Statistical analysis}

Continuous variables are presented as means (SD) and categorical variables as frequencies. For primary and secondary outcomes, groups were compared by Chi-square and Mann-Whitney tests for categorical and continuous variables, respectively. The Mann-Whitney test was used to assess the asymmetric distribution of the continuous variables. Fisher's exact test was used when the expected frequencies were too low. The effect of time on PROMs and ion levels within the groups (paired samples) was tested with the non-parametric Wilcoxon Signed Ranks Test. The significance level was defined as $p<0.05$. Statistical analyses were performed with SPSS 25.0 software (SPSS Inc., Chicago, IL, USA).

\section{Results}

Mean follow up for both groups was 14 years (12.1 to 14.7).

\section{Patient reported outcome measures (PROMs)}

Following an intent to treat analysis, including all cases (including revised cases), last follow-up, mean WOMAC scores were significantly better in the LDH THA group (94 vs $85, p=0.04$, Fig. 2, Table 2), and significantly more LDH THA patients reported no limitation with 


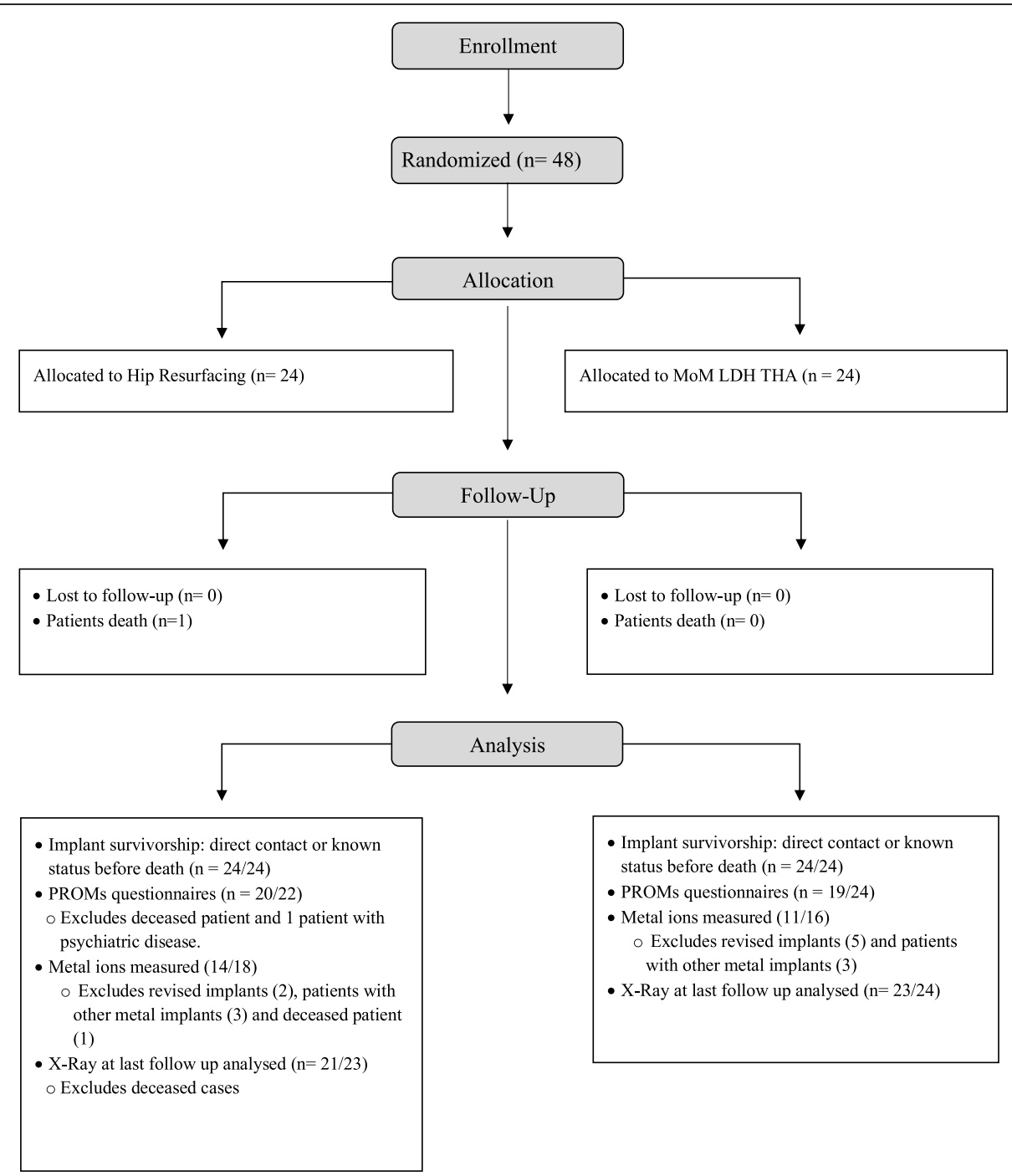

Fig. 1 The figure shows the flow chart of participants throughout the study

their artificial joints on the PJP question ( $\mathrm{p}=0.04$, Table 2). UCLA activity scores, FJS, and overall PJP results, were also higher for the LDH THA group but the difference did not reach a statistically significant difference (Fig. 2, Table 2). Between the 1-year and last follow-up evaluation, a significant deterioration was observed in both groups for WOMAC (HR, $p=0.004$; LDH THA, $p=0.04$ ). Similarly, UCLA activity scores deteriorated for the same period in both groups, reaching a statistical significance only in the LDH THA group ( $p=0.01$ ) (Fig. 2, Table 2).

When comparing PROMs of well-functioning implants (non-revised and without radiographic signs of implant dysfunction), LDH THA continues to demonstrate significantly better overall PJP results $(p=0.04)$, while the rest of the scores differences did not reach statistical significance (WOMAC nearly significant with $p=0.05$ ). Evaluating the effect of time between the 1-year and last follow-up evaluation, both HR and LDH THA had a significant WOMAC score deterioration $(p=0.004)$ (Fig. 2, Table 2).

\section{Revision rates}

The overall revision rate was $20.8 \%(5 / 24)$ for $\mathrm{LDH}$ THA and $8.3 \%(2 / 24)$ for HR $(p=0.4$, Fisher's exact test). In HR, 2 cases of femoral loosening occurred at 2.1 and 8 years after the initial procedure. One case was a woman with primary osteoarthritis, aged 47 years at the time of initial surgery. The bearing size was $44 \mathrm{~mm}$ and cup inclination were $42^{\circ}$. The loose femoral component was revised 2 years postoperatively to an uncemented primary stem with a MoM LDH matching the well-fixed acetabular component. Three years later, she developed trunnion related adverse reaction to metal debris (ARMD) and the bearing and the acetabular component 
Table 1 Pre- and peri-operative data for patients who received the allocated treatment

\begin{tabular}{|c|c|c|c|}
\hline \multirow[t]{2}{*}{ Factor } & \multirow{2}{*}{$\begin{array}{l}\mathrm{HR} \\
n=24\end{array}$} & \multirow{2}{*}{$\begin{array}{l}\text { LDH THA } \\
n=24\end{array}$} & \multirow[t]{2}{*}{$P$} \\
\hline & & & \\
\hline Gender (male/female) & $14 / 10$ & $15 / 9$ & 0.9 \\
\hline Primary diagnosis & & & 1 \\
\hline Primary osteoarthritis & 18 & 19 & \\
\hline Protrusio acetabuli & 1 & 1 & \\
\hline Post-traumatic arthritis & 1 & - & \\
\hline Hip dysplasia & 2 & 1 & \\
\hline Osteonecrosis & 1 & 2 & \\
\hline Rheumatoid arthritis & 1 & - & \\
\hline Post-septic arthritis & - & 1 & \\
\hline Age in years at surgery mean (SD) & $50(7.1)$ & $50(7.8)$ & 0.6 \\
\hline BMI mean (SD) & $28(5.9)$ & $28(4.1)$ & 1 \\
\hline Acetabular vertical angle mean (SD) & $49(7.5)$ & $43(8)$ & 0.01 \\
\hline HR femoral component CCD angle mean (SD) & $142(7.7)$ & - & - \\
\hline Acetabular cup diameter mean (SD) & $54(3.8)$ & $54(3.8)$ & 0.9 \\
\hline Bearing diameter, mean (SD) & $48(3.8)$ & $48(3.8)$ & 0.9 \\
\hline
\end{tabular}

HR Hip resurfacing, LDH THA Large diameter head total hip arthroplasty, BMI Body mass index, CCD Cervico diaphyseal angle

were re-revised to a ceramic on ceramic $(\mathrm{CoC})$ articulation, while the stem was retained. The second case was a man with primary osteoarthritis, aged 54 years at the time of surgery. He was implanted with a $48-\mathrm{mm}$ bearing with a cup inclination of $45^{\circ}$. He developed a loose femoral component 8 years postoperatively and had a bipolar revision with a CoC implant (Fig. 3).

In LDH THA, the reasons for revision included 4 ARMD cases and 1 deep infection that was treated by a two-stage revision at 8.8 years after the initial surgery. Revisions for ARMD were performed after a mean of 10.7 (9.3-11.3) years. The revised cases had mean levels of Co and Cr of $2.6 \mu \mathrm{g} / \mathrm{L}$ (1.4 to 4.5$)$ and $1.9 \mu \mathrm{g} / \mathrm{L}(1.2$ to 3.1), respectively, at 1 year and $2.8 \mu \mathrm{g} / \mathrm{L}$ (0.7 to 4.9$)$ and $1.5 \mu \mathrm{g} / \mathrm{L}$ (1.1 to 2$)$, respectively, before revision. The mean acetabular component abduction angle was $40^{\circ}$ $\left(36^{\circ}\right.$ to $\left.45^{\circ}\right)$. In all ARMD cases, we observed blackened corroded debris at the junction between the stem and

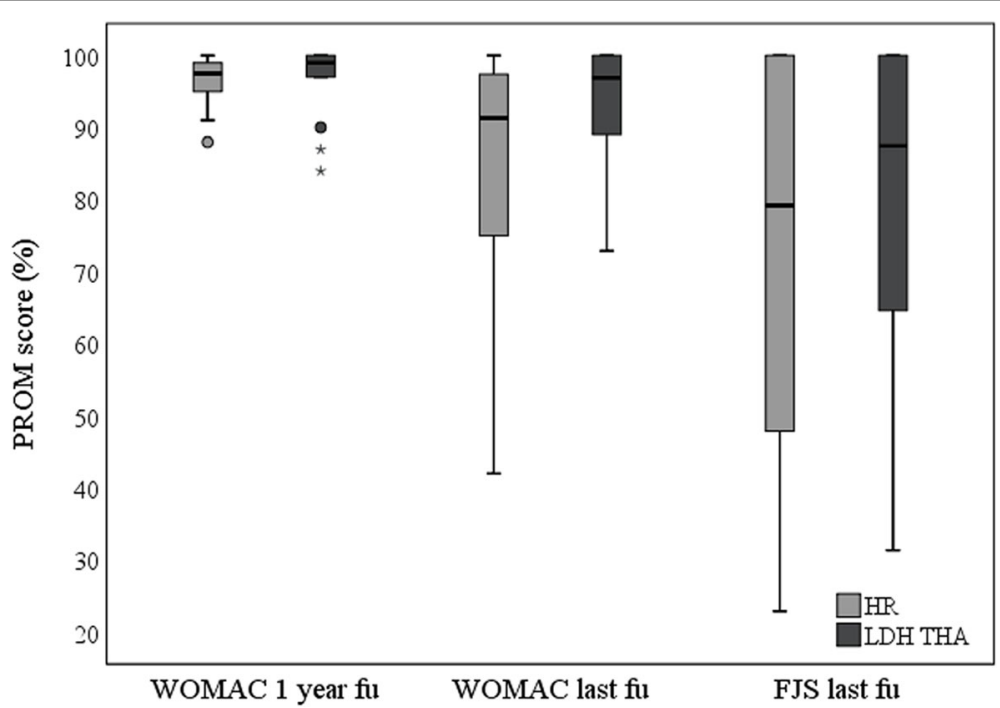

Fig. 2 Box plot chart of one-year and last follow-up WOMAC scores, and last follow-up FJS for patients with LDH THA or HR. WOMAC (higher values represent a better outcome). The line at the center of the boxes shows the median value. Box lengths represent the interquartile rage (1st to 3 rd quartiles). Data flagged by ${ }^{\circ}$ are outliers (being more than 1.5 to 3.0 times the interquartile range over the third quartile), and data indicated by ${ }^{*}$ are extreme values (more than 3 times the interquartile range over the third quartile) 
Table 2 Patient-reported outcome measures (PROMs) data, values are mean (SD) and $n$ for patient's joint perception (PJP)

\begin{tabular}{|c|c|c|c|c|c|c|c|c|c|}
\hline \multirow[t]{2}{*}{ PROMs } & \multicolumn{3}{|c|}{ One-year follow-up } & \multicolumn{3}{|c|}{ Last follow-up, all cases ${ }^{a}$} & \multicolumn{3}{|c|}{ Last follow-up, well-functioning cases ${ }^{b}$} \\
\hline & $\begin{array}{l}\text { HR } \\
(n=24)\end{array}$ & $\begin{array}{l}\text { LDH THA } \\
(n=24)\end{array}$ & $p$ & $\begin{array}{l}\mathrm{HR} \\
(n=20)\end{array}$ & $\begin{array}{l}\text { LDH THA } \\
(n=19)\end{array}$ & $p$ & $\begin{array}{l}\text { HR } \\
(n=17)\end{array}$ & $\begin{array}{l}\text { LDH THA } \\
(n=12)\end{array}$ & $p$ \\
\hline WOMAC & $97(8.4)$ & $98(8.5)$ & 0.2 & $85(16)$ & $94(7.8)$ & 0.04 & $89(11)$ & $96(5.3)$ & 0.05 \\
\hline UCLA Activity & $8.0(1.5)$ & $8.3(1.7)$ & 0.5 & $7.2(1.8)$ & $6.7(1.8)$ & 0.5 & $7.3(1.9)$ & $6.4(1.7)$ & 0.3 \\
\hline FJS & - & - & - & $80(27)$ & $80(21)$ & 0.5 & $80(21)$ & $85(14)$ & 0.7 \\
\hline PJP & & & 0.8 & & & $0.2^{*}$ & & & $0.04^{*}$ \\
\hline Natural hip & 15 & 14 & & 8 & 13 & & 8 & 9 & \\
\hline Artificial hip without limitation & 5 & 7 & & 4 & 4 & & 2 & 3 & \\
\hline Artificial hip with minimal limitation & 4 & 3 & & 7 & 2 & & 7 & 0 & \\
\hline Artificial hip with significant limitations & 0 & 0 & & 1 & 0 & & 0 & 0 & \\
\hline Non-functional hip & 0 & 0 & & 0 & 0 & & 0 & 0 & \\
\hline
\end{tabular}

HR Hip resurfacing, LDH THA Large diameter head total hip arthroplasty, FJS Functional joint score, PJP Patient's joint perception

all cases: non-revised, revised and cases with adverse events are included

bell-functioning cases: non-revised and without radiographic signs of dysfunction implants are included

*Regrouping the 4 categories in 2: "hip without limitation" and "hip with limitation", $p$ values are 0.04 for all cases and 0.01 for well-functioning cases in the last follow-up

A significant difference was present within each group between one-year and last follow up evaluations for WOMAC (HR, $p=0.004$; and LDH THA, $p=0.04$ ) for all cases. (Related-Sample Wilcoxon Signed Rank Test)

UCLA activity differences were significant only for the LDH THA group between one-year and last follow-up (HR, $p=0.5$; and LDH THA, $p=0.01)$ for all cases. (Related-Sample Wilcoxon Signed Rank Test)

WOMAC differences were significant only for the HR group between one-year and last follow-up (HR, $p=0.009$; and LDH THA, $p=0.3$ ) for well-functioning cases. (Related-Sample Wilcoxon Signed Rank Test)

the CoCr femoral head adapter sleeve. During revisions, all acetabular components were revised, and 1 out of the 4 femoral stems was retained; the implanted bearing was a $\mathrm{CoC} \mathrm{LDH}$ in 3 cases, and metal-on-polyethylene (MoP) in 1 case (Fig. 4). The ARMD revision rate was significantly higher in LDH THA $(16.7 \%$ versus $0 \% ; p=0.04)$.

\section{Other adverse events}

During the initial surgery, a hairline proximal femoral fracture occurred in 2 LDH THAs. Both were stabilized with cerclage wires intraoperatively and healed uneventfully with no postoperative restrictions. In HR, 1 patient developed a drop foot and paresthesia immediately postoperatively, that recovered gradually over the course of 2 years. In LDH THA, 1 patient had unexplained mild groin symptoms, fluid collections on MRI, and low and stable ion levels (Co $0.6 \mu \mathrm{g} / \mathrm{L}$ and $\mathrm{Cr} 1.5 \mu \mathrm{g} / \mathrm{L}$ ). ARMD is suspected, but no surgical intervention has occurred to date. The LDH THA patient revised for infection experienced a single episode of dislocation 6 months post revision, that was treated conservatively without recurrence.

\section{Metal ion levels}

Co concentrations were significantly higher for LDH THA compared to HR at 1-year and last follow-up ( $p=$

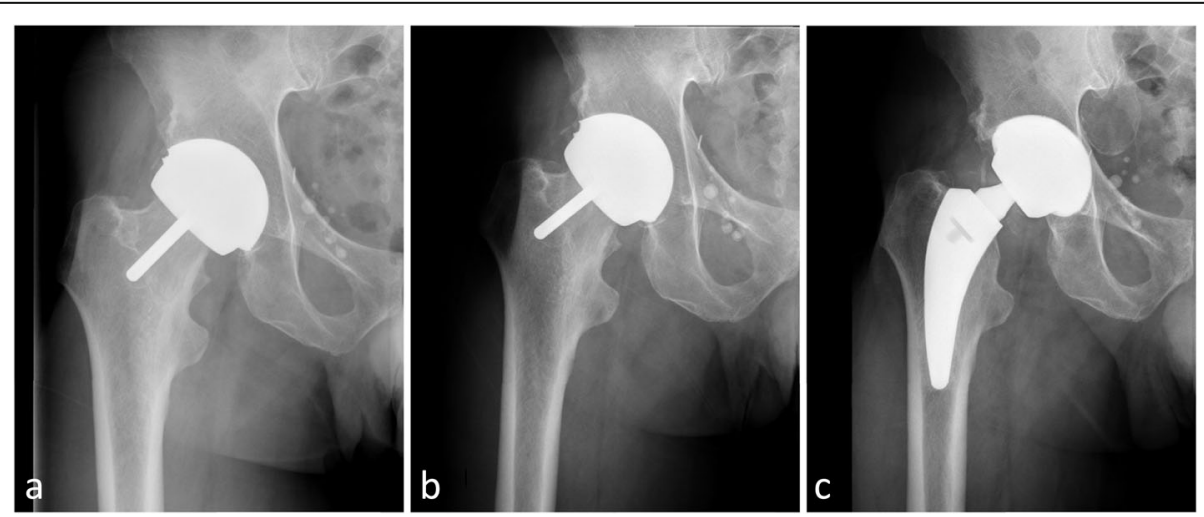

Fig. 3 a A 54-year-old man with osteoarthritis underwent implantation of hip resurfacing implant. An AP radiograph of the patient's right hip taken 4 months after surgery. $\mathbf{b}$ An AP radiograph of the patient's right hip taken 8 years postoperatively shows the femoral component is loose. c The patient underwent bipolar revision with a CoC implant 


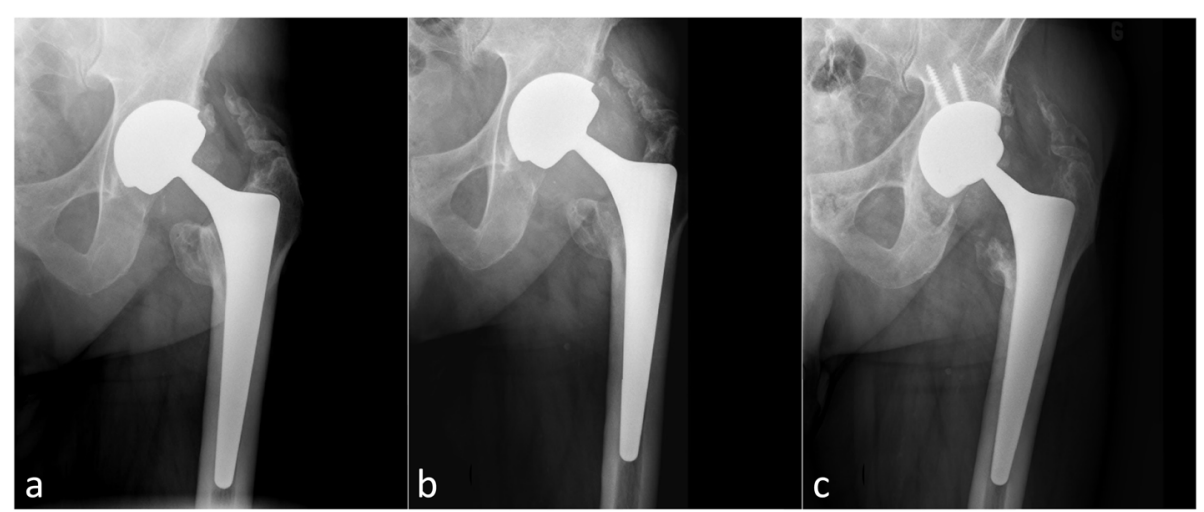

Fig. 4 a A 63-year-old man with osteoarthritis underwent implantation of large diameter total hip arthroplasty implant. An AP radiograph of the patient's left hip taken 1 month after surgery. $\mathbf{b}$ An AP radiograph of the patient's right hip taken 11 years postoperatively shows proximal femoral lysis. c The patient underwent bipolar revision with a CoC implant

$0.01, p=0.04$, Table 3). Cr levels were higher for LDH THA at 1-year and last follow-up, but statistical significance was not achieved ( $p=0.2$ and $p=0.1$, respectively). The mean $\mathrm{Co} / \mathrm{Cr}$ ratio was almost double for $\mathrm{LDH}$ THA, compared to HR at 1-year follow-up (1.5 vs 0.8 ; $\mathrm{p}=0.1)$ and last follow-up (1.9 vs $1.0 ; p=0.1)$, but did not reach statistical significance. Over time, $\mathrm{Co}$ and $\mathrm{Cr}$ levels increased between 1-year and last follow-up for LDH THA (Co $p=0.08$; Cr $p=0.2$ ) and for HR (Co $p=$ 0.06; Cr $p=0.4$ ) (Fig. 5, Table 3).

\section{Radiological evaluation}

At last follow-up, no acetabular component in either group was found to be loose. In HR, 1 femoral component ( $48 \mathrm{~mm}$ in diameter) in a female patient was considered to be loose. Interestingly, multiple cysts in the acetabulum and femoral head were present on the preoperative radiographs of this patients. This patient remains asymptomatic. Periprosthetic non-progressive (< $2 \mathrm{~mm}$ ) radiolucent lines were observed in 4/23 of $\mathrm{LDH}$ THA cases, in the proximal femur (Gruen zones 1,7, 8 or 14), while no stem was found to be loose. The presence of heterotopic ossification $(\mathrm{HO})$ was similar $(p=$ 0.9 ) in both groups (LDH THA 6/23 vs HR 6/21). None of the patients presenting with $\mathrm{HO}$ had any related symptoms. ARMD is suspected in $1 \mathrm{LDH}$ THA patient

Table 3 Whole blood Cobalt and Chromium levels at one-year and last follow-up, values $(\mu \mathrm{g} / \mathrm{L})$ are mean (SD)

\begin{tabular}{lllllllll}
\hline & \multicolumn{3}{l}{ One-year follow-up } & & & \multicolumn{3}{l}{ Last follow-up } \\
\cline { 2 - 3 } & HR & LDH THA & $\boldsymbol{p}$ & & HR & LDH THA & $\boldsymbol{p}$ \\
& $\boldsymbol{n}=\mathbf{1 6}$ & $\boldsymbol{n}=\mathbf{1 5}$ & & & $\boldsymbol{n}=\mathbf{1 4}$ & $\boldsymbol{n}=\mathbf{1 1}$ & \\
\hline Cobalt & $0.9(1)$ & $1.9(1.3)$ & 0.01 & $1.7(2)$ & $3.8(3.2)$ & 0.04 \\
Chromium & $1.2(0.9)$ & $1.5(0.8)$ & 0.2 & $1.4(1.1)$ & $1.9(1)$ & 0.1 \\
\hline
\end{tabular}

HR Hip resurfacing, $L D H T H A$ Large diameter head total hip arthroplasty, Cobalt (HR, $p=0.06$; and LDH THA $p=0.08)$ and Chromium (HR $p=0.4$; and $\mathrm{LDH}$ THA $p=0.2$ ) ion level differences were not significant between the oneyear and last follow-up. (Related-Sample Wilcoxon Signed Rank Test) with persisting groin pain, high metal ion levels (Co $10.1 \mu \mathrm{g} / \mathrm{L}$, and $\mathrm{Cr} 2.9 \mu \mathrm{g} / \mathrm{L}$ ) and multiple periprosthetic fluid collections on MRI. This patient is awaiting his revision surgery.

\section{Discussion}

The present study documented the long-term follow-up of an RCT comparing LDH THA and HR, both with identical MoM bearing. Assessing PROMS for all cases (including revised ones), LDH THAs provided better WOMAC scores, compared to HR, and patients more frequently reported no limitation with their artificial joints. We found higher revision rates in the LDH THA group and different reasons for revision in each group. The main reasons for revision were femoral head loosening for HRs and ARMD secondary to trunnionosis in LDH THAs. At the last follow-up, Co levels were significantly higher in LDH THA, whereas radiographic outcomes were similar.

\section{Study limitations}

This study has some limitations. First, when the study was designed, gait analysis was the primary outcome and power analysis was calculated accordingly. Interestingly, while this may have limited the power of the study, we could still find statistically significant results, and our data represent the longest findings published from an RCT comparing LDH THA to HR using the same bearing. Second, patients were kept blind to the type of prosthesis implanted for only 1 year after surgery. The impact of their knowledge of implanted components on PROMs after that time point is unknown. Third, patients were not systematically assessed by imaging techniques (ultrasound, MRI) to identify ARMD. It is likely that asymptomatic ARMDs were missed. 


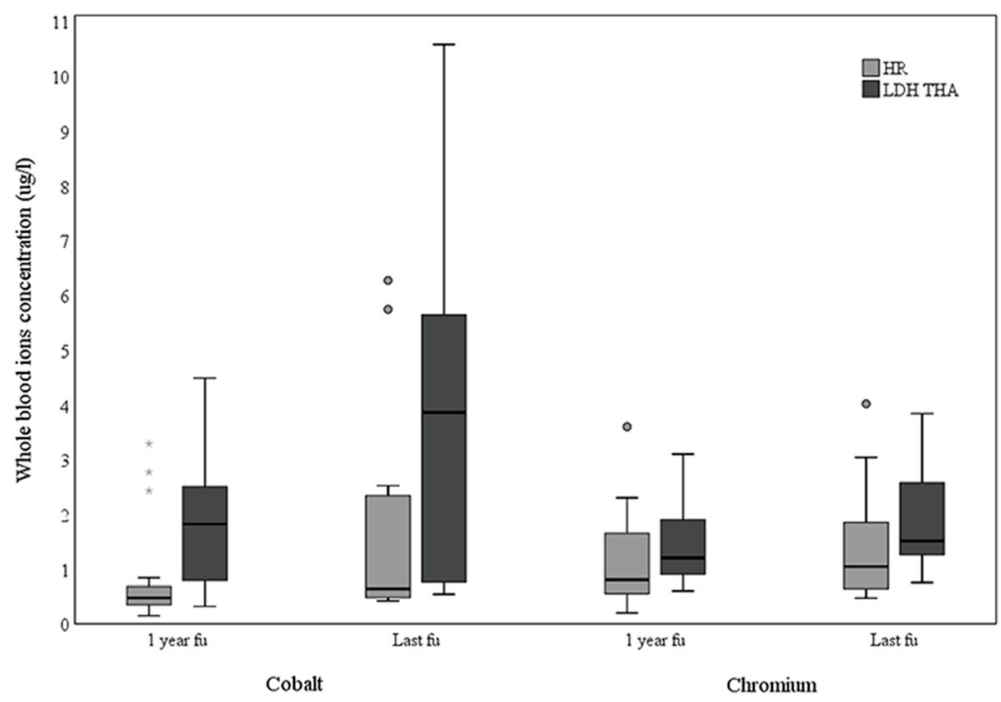

Fig. 5 Box plot chart of Cobalt and Chromium ion levels in whole blood of one-year and last follow-up for patients with LDH THA or HR. The line at the center of the boxes shows the median value. Box lengths represent the interquartile rage (1st to $3 r d$ quartiles). Data flagged by ${ }^{\circ}$ are outliers (being more than 1.5 to 3.0 times the interquartile range over the third quartile), and data indicated by * are extreme values (more than 3 times the interquartile range over the third quartile)

\section{PROMs}

In our study, all PROMs were higher in the LDH THA group, even though only WOMAC and the perception of no limitation on the PJP question reached a statistical significance (Table 2). In the LDH THA group, 1/19 patients had a WOMAC score $<80$, compared to $6 / 20$ in HR. When comparing WOMAC scores over time for all cases, we found a deterioration for both study cohorts (Table 2, Fig. 2). This may be explained by patients aging, or by the impact of surgical revision on the clinical scores. Interestingly, when we compared PROMs of patients with well-functioning implants, LDH THA was found to have better overall PJP results, but no significant differences in other PROMs (WOMAC was nearly significant with $p=0.05)$. However, there are some limitations to most validated PROMs and patients may feel their hip as "natural" without necessarily having better WOMAC scores [22]. The data from our current study do not provide a robust explanation for the differences in PROMs between groups in the long term. On the other hand, in the senior author's practice, when revising a HR into a LDH THA, most patients show preference to the revised hip. Similar subjective feedback is given by patients with a HR on one side and subsequently operated on the other side with a LDH THA. They all prefer the LDH THA side, mainly for its increase flexibility and greater range of motion. At a shorter follow up of 9 years, a similar RCT by Konan et al. [23], comparing 104 Durom HR or LDH THA, noted no difference in PROMs. Using a CoC LDH THA in 276 patients, our group, using the same surgical technique as in the current study, observed mean WOMAC score of 92.3,
UCLA activity score of 6.6, and FJS of 88.5 after a mean follow-up of 67 months [9]. These results are very similar to the well-functioning MoM LDH THA data of the current study (Table 2).

\section{Revision rates and other adverse events}

In our study, the reasons for revision were implant specific. All HR's revisions and failed implant on radiographic analysis were due to femoral component loosening (3/24). The failed femoral head diameters were all $\leq 48 \mathrm{~mm}$, which is considered an important risk factor for loosening [2, 12, 24]. Indeed, Durom HR was reported to have a higher rate of femoral head loosening compared to other HR implants and the US acetabular cup version (not used in the present study) was recalled by the manufacturer in 2008. In the LDH THA group, all revisions except 1 deep infection were performed for ARMD. In addition, there are 2 more patients with suspected ARMD: one of which is scheduled for surgery, while the other has mild symptoms and refuses further treatment, leading to a total ARMD rate of $25 \%$. LDHA THA sharing the same bearing as HR, adding the modular head introduced a problematic modular junction responsible for trunnionosis, and thus ARMD. Our macroscopic findings of blackened corroded debris at the head-neck junction at time of revision confirmed the failure mechanism. Higher failure rates were also reported with Durom LDH THA (28.9\%) in comparison to Durom HR (2.3\%) by Ridon et al. [25] after 10-year follow-up. Similarly, Konan et al. [23] after a mean follow-up of 9 years, reported a $2.1 \%$ revision rate in HR versus $12.5 \%$ in LDH THA. From these results we 
understand that the MoM LDH bearing was not the source of the failures. With an appropriate modular junction, it would provide low failure rate and then its stability benefits may become appealing.

Using a CoC LDH THA in 276 patients, we reported a revision rate of $1.4 \%$ after a mean follow-up of 67 months ( $\min 48, \max 79$ ) [9]. The 4 revisions were unrelated to the modular junction or the bearing. Furthermore, we did not observe radiographic or clinical signs of ARMD. To indirectly assess the performance of the modular junction of this specific CoC LDH THA, we measured the Ti level in 57 unilateral cases after a mean follow up of 79 months [26]. We observed low mean $\mathrm{Ti}$ levels (mean 1.9, SD 0.53), suggesting good modular junction performance. If the encouraging results of these studies are confirmed in the long term then the use of CoC LDH THA, would be a favorable alternative to HR in the young active patient. In recent years, $\mathrm{CoC}$ or $\mathrm{MoP}$ HR were also introduced but femoral head necrosis and loosening would stay unresolved $[8,27,28]$.

In our study no unrevised implant suffered a dislocation, highlighting the benefit of LDH THA and HR implants to reduce the dislocation and maximize range of motion. In a series of 1748 LDH THAs at a mean follow-up of 31 months, the dislocation rate was $0.05 \%$ [29]. In in a retrospective study comparing 559 conventional THAs and 248 LDH THAs at a mean follow-up of 5 years, the dislocation rate was $1.8 \%$ versus $0 \%$ respectively [30]. Similarly, in an RCT, we reported no dislocation rate in HR versus $3 \%$ in $28 \mathrm{~mm}$ THA [31]. Similarly, Pollard et al. in retrospective study, reported a dislocation rate of $7.4 \%$ among 54 THA compared to none in 54 HRs [1].

\section{Metal ion levels}

Systemic Co and $\mathrm{Cr}$ ions levels are an indirect way to assess the in vivo bearing and/or modular junction performance. Although both implants in our study had the same bearing, Co ion levels were significantly higher in LDH THA, whereas no statistical difference in Cr could be found (Table 3). Moreover, the $\mathrm{Co} / \mathrm{Cr}$ ratio was much higher in LDH THAs (1.9 vs 1.0). These differences can be explained by the poor performance of the modular junction of the Durom LDH THA. The wear and corrosion of the modular junction releases additional Co and $\mathrm{Cr}$ [32]. Part of the $\mathrm{Cr}$ wear particles precipitate locally, forming a black tartrate around the femoral neck, reducing the amount of $\mathrm{Cr}$ released systemically, explaining a higher whole blood $\mathrm{Co} / \mathrm{Cr}$ ratio and the lack of measured difference in systemic $\mathrm{Cr}$ between groups [33]. Ridon et al. [25] reported 6-fold higher Co $(p<0.0001)$ and increased $\mathrm{Cr}(p<0.0001)$ whole blood ion concentrations in patients with LDH THA compared to patients with $\mathrm{HR}$, when comparing the results of the same acetabular component (Durom) after more than 10 years' follow-up. Similarly, in a RCT evaluating the Durom system at 1 year postoperatively, patients with a LDH THA had 10-fold higher serum Co levels $(p=0.000)$ compared to patients with $\mathrm{HR}$, and no difference for $\mathrm{Cr}$ levels [34]. Finally, metal ion levels were not statistically different over time in both groups, indicating that the unrevised LDH THA and HR prostheses continue to perform well in the long-term follow-up.

\section{Radiographic analysis}

On radiographic evaluation at the last follow-up, all components were considered to be stable, except for 1 asymptomatic HR with a loose femoral component. Lucent lines on the femoral side were not seen in other HR, whereas proximal non-progressive femoral radiolucent lines observed in the LDH THA cases are known to be linked to normal long-term bone remodeling pattern of the CLS stem [35]. These results are reassuring as the remaining unrevised cases seem to be producing limited wear particles and should continue to do so in the future.

HR has been proposed as a great treatment option for the high expectations' young patients. On the other hand, its indications may be limited in presence of secondary osteoarthritis associated with anatomical challenges, such as acetabular retroversion, hip dysplasia, femoral retroversion, Perthes, and pistol-grip deformity. LDH THA replacing the femoral head-neck pathological anatomy and offering a supraphysiologic head-neck ratio has the advantage of simplifying these complex cases [36].

\section{Conclusion}

In this RCT comparing HR and LDH THA using the same bearing, after a mean of 14 years' follow-up, LDH THA had a higher revision rate, linked to its modular junction wear and corrosion. However, the LDH THA group had still better PROMs compared to the HR group. LDH THA with a new modular junction design and/or ceramic bearing, obviating the trunnion issues would be a more appealing option than HR for our young and demanding patients.

\section{Abbreviations \\ ARMD: Adverse reaction to metal debris; CoC: Ceramic on ceramic; FJS: Forgotten joint score; HR: Hip resurfacing; LDH: Large diameter head; MoM: Metal on metal; MoP: Metal on polyethylene; PJP: Patient's joint perception; PROMs: Patient reported outcome measures; THA: Total hip arthroplasty}

\section{Acknowledgments}

We thank Dr. Alain Roy who contributed to the surgical procedures.

\section{Authors' contributions}

LK is the first author and was involved in data curation, formal analysis, writing the original draft, and review and editing the final manuscript. P-AV is the senior and corresponding author and was involved in funding acquisition, conceptualization, data curation, formal analysis, writing the original 
draft, and review and editing the final manuscript. ML was involved in conceptualization, data curation and reviewing the draft manuscript. JB, MS and $\mathrm{M}-\mathrm{O} \mathrm{K}$ were involved in data curation, formal analysis and draft and final manuscript review. The authors read and approved the final manuscript.

\section{Funding}

The current report was undertaken with an unrestricted grant from the Maisonneuve-Rosemont Hospital Foundation. A specific research grant was received from Zimmer for the study implementation and previous analyses (2010 publication). The authors have no potential conflict of interest.

\section{Availability of data and materials}

The datasets used and analyzed during the current study are available from the corresponding author on reasonable request.

\section{Declarations}

\section{Ethics approval and consent to participate}

The procedures performed in this study, involving human participants, were in accordance with the latest amendments of the Declaration of Helsinki and the CONSORT statement. The research protocol was approved by Comité d'éthique de la recherche CIUSSS de l'Est-de-l'île-de-Montréal (Projet no 2016-391, 04132) and all.

subjects gave written informed consent before participating in the study.

\section{Consent for publication}

Not Applicable.

\section{Competing interests}

ML has received funding from Microport inc, Stryker Orthopaedics, Medacta, Smith \& Nephew, and Zimmer. P-AV has received funding from Microport inc, Stryker Orthopaedics, Medacta, Johnson \& Johnson, and Zimmer.

Received: 9 November 2020 Accepted: 22 April 2021

Published online: 30 April 2021

\section{References}

1. Pollard TC, Baker RP, Eastaugh-Waring SJ, Bannister GC. Treatment of the young active patient with osteoarthritis of the hip. A five- to seven-year comparison of hybrid total hip arthroplasty and metal-on-metal resurfacing. J Bone Joint Surg (Br). 2006;88(5):592.

2. Lavigne M, Therrien M, Nantel J, Roy A, Prince F, Vendittoli PA. The john charnley award: the functional outcome of hip resurfacing and large-head THA is the same: a randomized, double-blind study. Clin Orthop Relat Res. 2010;468(2):326-36.

3. Australian Orthopaedic Association. National joint replacement registry. Annual report. 2019. https://aoanjrr.sahmri.com/documents/10180/668596/ Hip\%2C+Knee+\%26+Shoulder+Arthroplasty/c287d2a3-22df-a3bb-37a2-91 e6c00bfcf0. Assessed 26 Jun 2020.

4. National joint registry for England, Wales, Northern Ireland and the Island of Man. Annual Report. 2019. https://reports.njrcentre.org.uk/Portals/0/ PDFdownloads/NJR16thAnnualReport2019.pdf. Assessed 26 Jun 2020.

5. $\mathrm{Ng}$ VY, Arnott L, McShane MA. Perspectives in managing an implant recall: revision of 94 durom metasul acetabular components. J Bone Jt Surg Am. 2011;93(17):5-9.

6. Cohen D. Out of joint: the story of the ASR. BMJ. 2011;342:d2905.

7. Sidaginamale RP, Joyce TJ, Bowsher JG, Lord JK, Avery PJ, Natu S, et al. The clinical implications of metal debris release from the taper junctions and bearing surfaces of metal-on-metal hip arthroplasty. Bone Joint J. 2016; 98B(7):925-33.

8. Farrier AJ, Moore L, Manning W, Avila C, Collins SN, Holland J. Comparing the cup deformation following implantation of a novel ceramic-on-ceramic hip resurfacing bearing to a metal standard in a cadaveric model. Proc Inst Mech Eng H. 2019;233(6):603-10.

9. Blakeney WG, Beaulieu Y, Puliero B, Lavigne M, Roy A, Massé V, et al. Excellent results of large-diameter ceramic-on-ceramic bearings in total hip arthroplasty: is squeaking related to head size? Bone Joint J. 2018;100B(11): 1434-41.

10. Bellamy N, Buchanan WW, Goldsmith CH, Campbell J, Stitt LW. Validation study of WOMAC: a health status instrument for measuring clinically important patient relevant outcomes to antirheumatic drug therapy in patients with osteoarthritis of the hip or knee. J Rheumatol. 1988;15(12): 1833-40.

11. Amstutz HC, Thomas BJ, Jinnah R, Kim W, Grogan T, Yale C. Treatment of primary osteoarthritis of the hip. A comparison of total joint and surface replacement arthroplasty. J Bone Joint Surg Am. 1984;66(2):228-41.

12. Behrend $\mathrm{H}$, Giesinger K, Giesinger JM, Kuster MS. The "forgotten joint" as the ultimate goal in joint arthroplasty. Validation of a new patient-reported outcome measure. J Arthroplast. 2012;27(3):430-6.

13. Collins M, Lavigne M, Girard J, Vendittoli PA. Joint perception after hip or knee replacement surgery. Orthop Traumatol Surg Res. 2012;98(3):275-80.

14. Harris WH, McCarthy JC, O'Neill DA. Femoral component loosening using contemporary techniques of femoral cement fixation. J Bone Joint Surg Am. 1982;64(7):1063-7.

15. Malchau H, Kärrholm J, Wang $Y X$, Herberts $P$. Accuracy of migration analysis in hip arthroplasty digitized and conventional radiography, compared to radiostereometry in 51 patients. Acta Orthop Scand. 1995;66(5):418-24.

16. Gruen TA, McNeice GM, Amstutz HC. "Modes of failure" of cemented stemtype femoral components. A radiographic analysis of loosening. Clin Orthop Relat Res. 1979;141:17-27.

17. Massin P, Schmidt L, Engh C. Evaluation of cementless acetabular component migration: an experimental study. J Arthroplast. 1989;4(3): 245-51.

18. Brooker A, Bowerman J, Robinson R, Riley LH Jr. Ectopic ossification following total hip replacement: incidence and a method of classification. J Bone Joint Surg Am. 1973;55(8):1629-32.

19. Amstutz HC, Beaulé PE, Dorey FJ, Le Duff MJ, Campbell PA, Gruen TA. Metal-on-metal hybrid surface arthroplasty: two to six-year follow-up study. J Bone Joint Surg Am. 2004;86(1):28-39.

20. Hirakawa K, Mitsugi N, Koshino T, Saito T, Hirasawa Y, Kubo T. Effect of acetabular cup position and orientation in cemented total hip arthroplasty. Clin Orthop Relat Res. 2001;388:135-42.

21. Dumbleton $\mathrm{JH}$, Manley MT, Edidin AA. A literature review of the association between wear rate and osteolysis in total hip arthroplasty. J Arthroplast. 2002;17(5):649-61.

22. Puliero B, Blakeney WG, Beaulieu Y, Vendittoli PA. Joint perception after Total hip arthroplasty and the forgotten joint. J Arthroplast. 2019;34(1): $65-70$.

23. Konan S, Waugh C, Ohly N, Duncan CP, Masri BA, Garbuz DS. Mid-term results of a prospective randomised controlled trial comparing large-head metal-on-metal hip replacement to hip resurfacing using patient-reported outcome measures and objective functional task-based outcomes. HIP Int. 2020;11:1. https://doi.org/10.1177/1120700020919671 Epub ahead of print. PMID: 32390475

24. Jameson SS, Baker PN, Mason J, Porter ML, Deehan DJ, Reed MR. Independent predictors of revision following metal-on-metal hip resurfacing: a retrospective cohort study using national joint registry data. J Bone Joint Surg (Br). 2012;94B(6):746-54.

25. Ridon PE, Putman S, Migaud H, Berton C, Pasquier G, Girard J. Long-term comparative study of large-diameter metal-on-metal bearings: resurfacing versus total arthroplasty with large-diameter Durom ${ }^{\mathrm{TM}}$ bearing. Orthop Traumatol Surg Res. 2019;105(5):943-8.

26. Eichler D, Barry J, Lavigne M, Massé V, Vendittoli PA. No radiological and biological sign of trunnionosis with large diameter head ceramic bearing total hip arthroplasty after 5 years. Orthop Traumatol Surg Res. 2020;107(1): 102543. https://doi.org/10.1016/j.otsr.2019.12.015 Epub ahead of print. PMID: 32276843

27. Farrier AJ, Moore L, Manning W, Avila C, Collins SN, Holland J. Comparison study of temperature and deformation changes in the femoral component of a novel ceramic-on-ceramic hip resurfacing bearing to a metal standard, using a cadaveric model. Proc Inst Mech Eng H. 2019;233(12):1318-26.

28. Treacy RBC, Holland JP, Daniel J, Ziaee H, McMinn DJW. Preliminary report of clinical experience with metal-on-highly-crosslinkedpolyethylene hip resurfacing. Bone Joint Res. 2019;8(10):443-50.

29. Lombardi AV, Skeels MD, Berend KR, Adams JB, Franchi OJ. Do large heads enhance stability and restore native anatomy in primary total hip arthroplasty? Clin Orthop Relat Res. 2011 Jun;469(6):1547-53.

30. Stroh DA, Issa K, Johnson AJ, Delanois RE, Mont MA. Reduced dislocation rates and excellent functional outcomes with large-diameter femoral heads. J Arthroplast. 2013;28(8):1415-20.

31. Vendittoli PA, Ganapathi M, Roy AG, Lusignan D, Lavigne M. A comparison of clinical results of hip resurfacing arthroplasty and $28 \mathrm{~mm}$ metal on metal 
total hip arthroplasty: a randomised trial with 3-6 years follow-up. HIP Int. 2010;20(1):1-13.

32. Vendittoli PA, Amzica T, Roy AG, Lusignan D, Girard J, Lavigne M. Metal ion release with large-diameter metal-on-metal hip arthroplasty. J Arthroplast. 2011;26(2):282-8.

33. Hothi HS, Berber R, Whittaker RK, Blunn GW, Skinner JA, Hart AJ. The relationship between cobalt/chromium ratios and the high prevalence of head-stem junction corrosion in metal-on-metal Total hip arthroplasty. J Arthroplast. 2016;31(5):1123-7.

34. Garbuz DS, Tanzer M, Greidanus NV, Masri BA, Duncan CP. The John Charnley award: metal-on-metal hip resurfacing versus large-diameter head metal-on-metal total hip arthroplasty: a randomized clinical trial. Clin Orthop Relat Res. 2010;468(2):318-25.

35. Rivière C, Grappiolo G, Engh CA, Vidalain J-P, Chen A-F, Boehler N, et al. Long-term bone remodelling around 'legendary' cementless femoral stems. EFORT Open Rev. 2018;3(2):45-57.

36. Lavigne M, Ganapathi M, Mottard S, Girard J, Vendittoli PA. Range of motion of large head total hip arthroplasty is greater than $28 \mathrm{~mm}$ total hip arthroplasty or hip resurfacing. Clin Biomech. 2011;26(3):267-73.

\section{Publisher's Note}

Springer Nature remains neutral with regard to jurisdictional claims in published maps and institutional affiliations.

Ready to submit your research? Choose BMC and benefit from:

- fast, convenient online submission

- thorough peer review by experienced researchers in your field

- rapid publication on acceptance

- support for research data, including large and complex data types

- gold Open Access which fosters wider collaboration and increased citations

- maximum visibility for your research: over $100 \mathrm{M}$ website views per year

At $\mathrm{BMC}$, research is always in progress.

Learn more biomedcentral.com/submissions 